\begin{tabular}{|c|c|c|}
\hline INESEG & $\begin{array}{l}\text { INTERNATIONAL } \\
\text { ENGINEERING, } \\
\text { SCIENCE AND } \\
\text { EDUCATION } \\
\text { GROUP }\end{array}$ & $\begin{array}{l}\text { Middle East Journal of Science } \\
\begin{array}{l}\text { (2017) 3(2): } 129 \text { - } 139 \\
\text { Published online December 25, } 2017 \quad \text { (http://dergipark.gov.tr/mejs) } \\
\text { doi: } 10.23884 / \text { mejs.2017.3.2.07 } \\
\text { ISSN: } 2536-5312 \\
\text { Received: September 26, } 2017 \quad \text { Accepted: November 11, } 2017\end{array}\end{array}$ \\
\hline
\end{tabular}

\title{
EDUCATION CAN BE A RESEARCH SUBJECT TOO, THROUGH SCIENTIFIC TEACHING
}

Justin FENDOS ${ }^{1,2}$

\author{
${ }^{1}$ Tan School of Genetics, Fudan University, Shanghai, China \\ ${ }^{2}$ Global Biotechnology Department, Dongseo University, Busan, South Korea \\ Corresponding author: Justin Fendos, jfendos@ aya.yale.edu
}

\begin{abstract}
In the last few decades, many important discoveries have been made in the field of education research. Few have been more influential than Dr. Donald Bligh's discovery that lectures are an inefficient method for student retention of new information. In the years following Dr. Bligh's discovery, science education in the US has witnessed a significant change in focus away from lecture-styled approaches that emphasize memorization towards interactive approaches focusing more on the training of skill competence. A range of research has employed the principles of scientific teaching with great success to investigate a wide array of different learning methods, resulting in the development of powerful education platforms such as active learning and authentic research experiences (AREs). This article reviews some of the education literature behind scientific teaching, active learning, and AREs, ending with a short commentary about the immense potential for the application of these systems in higher education in the Middle East, both as a process of improving educational outcome as well as enhancing the efficacy of pedagogy as a research subject.
\end{abstract}

Keywords: scientific teaching, active learning, STEM education, authentic research experiences, education research

\section{Education as research.}

In the last few decades, many important discoveries have been made in the field of education research. Few have been more influential than Dr. Donald Bligh's discovery that lectures are inefficient methods for students to retain new information [1, 2]. Not surprisingly, Dr. Bligh's results were greeted with some degree of skepticism [3, 4]. However, follow-up research conducted by a number of other authors has since confirmed that most students tend not to remember much when taught using a lecturestyled format [5-7]. This ineffectiveness has been demonstrated in knowledge learning [8-10] and found to be an even greater issue in skill learning [11-13]. In academic fields such as the sciences, which rely on the acquisition of laboratory expertise, skill learning is especially important, often considered a basic foundation for training good scientists [14-16].

In the years following Dr. Bligh's discovery, science education in the US has witnessed a significant change in focus away from lecture-styled approaches that focus on knowledge towards interactive approaches focused more on skill training [17, 18]. In 2004, Dr. Jo Handelsman and colleagues published their seminal paper in Science entitled "Scientific teaching". This paper described the critical importance of using scientific methods to investigate the effectiveness of pedagogy $[19,20]$. 
This process essentially involves designing and conducting experiments on various learning methods to produce statistically relevant data about educational outcomes, data that allows a determination about whether the methods were effective. As coined in the title of their paper, this process is known as scientific teaching.

Since this seminal work by Dr. Handelsman, a wide range of research has employed the principles of scientific teaching with great success to investigate many different learning methods [21, 22]. The use of technology in the classroom, for example, has been one of the areas studied extensively [23-25], as has the use of class activities employing group discussion strategies [26-28]. Both of these concepts, when employed in the right way, have been shown to be extremely successful in improving learning gains. The usefulness of inquiry-based learning systems [29, 30] and the development of new techniques for helping students understand and approach primary literature [31, 32] have been some of the many significant improvements in science education. In the US, many of these new learning techniques have been joined into different combinations to realize significant improvements in student outcomes, both in the classroom [33, 34] and on an institutional level [35].

\section{What is active learning?}

One of the combinations of new learning methods that has been particularly powerful and influential in the US is active learning [36, 37]. At its roots, the active learning system involves redesigning the activities occurring in-class to improve student interactions and feedback by implementing controlled problem-solving activities [38, 39]. These activities are specifically designed to focus student and instructor attention on the process of learning how to apply knowledge rather than simply memorize it, the latter of which is usually the goal in a lecture-based system. By emphasizing the majority of in-class time on problem-solving, active learning gives students the chance to receive more feedback and attention from instructors in developing their knowledge-use skills [40].

The strengths and advantages of active learning have been studied extensively in the last decade. Across the board, active learning has been shown to be very effective in improving learning gains [41, $35]$, yielding better student grades [42, 6], improving the retention of class material $[43,44]$, and even improving student interest levels in various topics [45, 46]. A central principle of the active learning system is the idea of a "flipped classroom", a concept sometimes also referred to as "reverse design" [47-49]. A flipped classroom describes a situation in which the traditional in-class and out-of-class activities are reversed.

In traditional lecture classes, for example, new material is usually presented to students in class through lectures. In most science classes, out-of-class time is then used by students to work on assigned problems sets. These problems sets require the students to apply things they were shown in the lectures. There are two main shortcomings that arise through this traditional arrangement. The first is found in the simple fact that students do not tend to remember much of what they were told in lectures. We know this from Dr. Bligh's original work and in the wealth of follow-up research [1, 2, 5-7]. Since the problem sets require students to have this foundational knowledge, the lack of retention from lectures puts a lot of pressure on them to learn the bulk of the material by themselves. The second shortcoming is found in the fact that students receive very little feedback when they are working on the problem sets, making 
the acquisition of problem-solving skills an independent endeavor with little instructor oversight [50, $51]$.

In the active learning system, this traditional arrangement of activities is flipped. In active learning, new material is introduced to students outside of the class, usually through online lectures or assigned readings $[52,53]$. At the same time, the problem sets become in-class activities. Not only does this new arrangement allow for more feedback from instructors, the installation of a group problemsolving environment, another common element of active learning, allows for students to receive feedback from each other, allowing for much better retention of the material and faster learning $[54,6]$. This allows the process of cooperative learning to enhance the pedagogical process while simultaneously bringing the more difficult of the two tasks--namely, learning new material and then applying it--under the direct supervision of instructors. Since most exams in science usually involve assessments of problem-solving ability, this rearrangement can also result in direct improvements of student grades [42, $6]$.

\section{Assessments for educational outcomes}

Because of the wide range of different learning approaches and the staggering breadth of things that students need to learn, a very active area of current education research has revolved around the design and implementation of new assessment tools which attempt to quantify student outcomes with statistical significance [55-57]. As described above, such tools have been used to quantify things such as student retention of new material [58-60] and problem-solving skill competence [61-63]. Both of these types of tools have been very important in establishing the usefulness of scientific teaching.

Another active area of research has been the design and implementation of tools that gauge student attitudes about classes, learning methods, instructors, and curricula [64-67]. These tools have been especially useful in uncovering the power of cooperative learning [68-70] while also allowing educational researchers to realize that there can exist a wide range of variability in the ways different students respond to the same teaching technique, even when this technique is applied in the same way to the same academic subject. These results have had significant implications in helping educators better understand the conditions that facilitate more inclusive learning [71-73].

Perhaps the rapid expansion of new assessment tool development is one of the most significant and important innovations driven by scientific teaching [74, 75]. Not only is the study and design of new tools currently a cutting-edge topic in education research, the deployment of existing tools in new situations or new cultural contexts is one of the concepts with wide reaching applicability, an untapped opportunity for education researchers in most countries, especially those with emerging education infrastructure. An especially interesting area of development is the construction and deployment of assessments for measuring skill competence [76, 77]. Recent developments in this area have clearly indicated that skill competence is something that needs to be measured with focused specificity. For example, an assessment that measures a student's ability to understand and apply genetics knowledge on paper does not necessarily predict that student's ability to use this knowledge in the lab, creating an important distinction about the relationships between discrete skills, creating the need for many different assessments. 
In a general sense, perhaps the most important lesson to be learned from the abundance of education research hitherto generated through scientific teaching is the idea that just having the instructor explain something is not enough. Most teachers often subscribe to the misconception that explaining something once or twice should be sufficient for students to remember that information accurately and over long periods of time. Scientific teaching research clearly shows this is not true [78, 79]. Instead, a common thread that has emerged from the research is that the long-term retention of new material seems to require students to apply that information in some way, usually more than once, a goal that active learning is specifically designed to achieve [38, 39]. The distinctions between a student's recognition of a new word, his or her ability to define it, and the ability to apply it are things presented in self-evident fashion in Bloom's pyramid, a conceptual model found in psychology that organizes these and other modes of thinking into a structured hierarchy, showing that one must precede the other, something that has now been confirmed experimentally [80, 81].

\section{Authentic research experiences}

Active learning is not the only implement in science education that can be used to focus more time and attention on skill development. In traditional science education, classes are typically divided into two types: lecture and lab. Lectures are where new content knowledge is supposed to be delivered whereas labs are where students are expected to apply this new knowledge. The problem with traditional lab classes is that they are built like cookbooks, with everything explained beforehand and nothing new for students to discover $[82,83]$. This is despite the fact that many science students actually join science because of their desire to discover, often leaving many disappointed about the lack of discovery-oriented intellectual stimulation in their course work $[84,85]$.

In the last few years, some universities such as Yale and Stanford, have started to implement new types of lab courses that specifically gives students the chance to make discoveries [86, 87]. One of these new types is something called the authentic research experience (ARE). An ARE is a lab course that is designed around a real research question that gives students the chance to discover. This inquirybased approach is especially advantageous in lab classes because they allow students to practice critical research skills that would otherwise not be practiced in a traditional cookbook lab [88-90]. For example, in a cookbook lab, students are usually given a lab manual that explains everything that could possibly happen with their experiment, depriving them of the chance to make predictions about the experiment or troubleshoot problems, two critical skills that need to be practiced.

In an ARE, on the other hand, students do not possess this information. Instead, they are given an experimental question and some guidelines with which to make decisions about how they will conduct the experiment, resulting in a more realistic simulation of real research, a process that invariably requires the participants to deal with various levels of the unknown. At each step in the experiment, students are allowed to think about that step, sometimes by making hypotheses or designing experimental parameters while, at other times, implementing those parameters and troubleshooting the results. This process allows for a much more "authentic" experience in which students practice more of the actual research skills they will need as researchers. In addition to the improvement in the skills practiced, AREs also give students a strong sense of ownership over their experiments, heightening the level of satisfaction and enjoyment while stimulating the desire to discover and learn through discovery [88-90]. 
If designed well, an ARE can be used as a platform for generating real experimental data. Fudan University, for example, has recently implemented a large-scale ARE program called BIOS [91]. This program is a summer ARE with six topical tracks: biochemistry, cell biology, fly genetics, fish genetics, mouse genetics, and plant biology. Undergraduate participants receive training in two of these tracks over a period of eight weeks. Not only do the experiments in each track function as practice and lab training, some also yield real results of scientific significance, results that research labs are interested in. By training the students in the techniques that generate these results, the BIOS program functions as a focused system for training students in skills that are in demand by real research labs, labs that also participate in the training process by volunteering graduate students to work as teaching assistants.

\section{Opportunities outside the US}

Despite the significant amount of time during which scientific teaching has been developed and employed in the US, its use in other countries has been sluggish. In European countries, for example, a general awareness of flipped classrooms has only just begun to take hold. Nevertheless, it remains a fact that the vast majority of scientific teaching research is predominantly of US origin. One of the main reasons for this difference can be found in the lack of a centralized institution in Europe that active supports the dissemination of knowledge about scientific teaching. In the US, this role is taken up by the Howard Hughes Medical Institute (HHMI). Over the last few decades, HHMI has invested hundreds of millions of dollars into the development of various scientific teaching and active learning programs, a level of support that European countries simply have not yet enjoyed [92, 93].

The level of scientific teaching awareness in Asia has been very similar to that in Europe, characterized by some recognition of key concepts and the lack of a centralized authority actively pushing for reforms. Even in the sciences, an academic area that countries such as Japan, South Korea, and China have generally shared a favorable global reputation for, the implementation of class designs with scientific teaching or active learning principles remain almost totally non-existent. The concept of a flipped classroom has been implemented to various degrees in a few isolated academic settings, but these implementations have been met with mixed results usually leaning towards the negative. A main reason for these failures can be found in the fact that these class flipped designs have generally been implemented alone, without the simultaneous inclusion of other critical aspects of the active learning system such as statistically significant assessments or the installation of a cooperative learning environment that enhances feedback and interactivity.

Given the convincing nature and wealth of experimental support for the advantages of scientific teaching and active learning, it becomes difficult to say that the adoption of these two platforms outside of the US, especially in science classes, can be anything other than inevitable. For countries in the Middle East, the implementation and application of these new principles should be a significant step in improving the quality of education through enhancements of student outcome. From a policy and leadership perspective, there exists immense potential for a few diligent educators to take up the cause of scientific teaching and be the first to begin the implementation of these advanced forms of pedagogy. Not only will this courage be rewarded with the development of a new area of research in the region but the fruits of this labor will go to benefiting those who are the most important and most deserving: our students. 


\section{References}

[1] Bligh, Donald. "What's the use of lectures?." Journal of Geography in Higher Education 9, no. 1 (1985): 105-106.

[2] Bligh, Donald A. What's the Use of Lectures?. Intellect books, 1998.

[3] Wilson, Karen, and James H. Korn. "Attention during lectures: Beyond ten minutes." Teaching of Psychology 34, no. 2 (2007): 85-89.

[4] Matheson, Catherine. "The educational value and effectiveness of lectures." The Clinical Teacher 5, no. 4 (2008): 218-221.

[5] McCarthy, J. Patrick, and Liam Anderson. "Active learning techniques versus traditional teaching styles: Two experiments from history and political science." Innovative Higher Education24, no. 4 (2000): 279-294.

[6] Armbruster, Peter, Maya Patel, Erika Johnson, and Martha Weiss. "Active learning and studentcentered pedagogy improve student attitudes and performance in introductory biology." CBE-Life Sciences Education 8, no. 3 (2009): 203-213.

[7] Niemi, Hannele. "Active learning — a cultural change needed in teacher education and schools." Teaching and teacher education 18, no. 7 (2002): 763-780.

[8] Laws, Priscilla W. "Calculus-based physics without lectures." Physics today 44, no. 12 (1991): 2431.

[9] Sivan, Atara, Roberta Wong Leung, Chi-ching Woon, and David Kember. "An implementation of active learning and its effect on the quality of student learning." Innovations in Education and Teaching International 37, no. 4 (2000): 381-389.

[10] Powell, Kendall. "Science education: spare me the lecture." Nature 425, no. 6955 (2003): 234236.

[11] Hake, Richard R. "Lessons from the physics-education reform effort." arXiv preprint physics/0106087 (2001).

[12] Handelsman, Jo, Barbara Houser, and Helaine Kriegel. Biology brought to life: a guidebook to teaching students to think like scientists. McGraw-Hill Primis, 1997.

[13] Pukkila, Patricia J. "Introducing student inquiry in large introductory genetics classes." Genetics 166, no. 1 (2004): 11-18.

[14] Roth, Wolff-Michael, and Anita Roychoudhury. "The development of science process skills in authentic contexts." Journal of Research in Science Teaching 30, no. 2 (1993): 127-152.

[15] Harlen, Wynne. "Purposes and procedures for assessing science process skills." Assessment in Education: principles, policy \& practice 6, no. 1 (1999): 129-144.

[16] Padilla, Michael J. "The Science Process Skills. Research Matters... To the Science Teacher." (1986).

[17] Hofstein, Avi, and Vincent N. Lunetta. "The laboratory in science education: Foundations for the twenty-first century." Science education 88, no. 1 (2004): 28-54.

[18] Alfieri, Louis, Patricia J. Brooks, Naomi J. Aldrich, and Harriet R. Tenenbaum. "Does discoverybased instruction enhance learning?." (2011): 1. 
[19] Handelsman, Jo, Diane Ebert-May, Robert Beichner, Peter Bruns, Amy Chang, Robert DeHaan, Jim Gentile et al. "Scientific teaching." Science 304, no. 5670 (2004): 521-522.

[20] Miller, Sarah, Christine Pfund, Christine Maidl Pribbenow, and Jo Handelsman. "Scientific teaching in practice." Science 322, no. 5906 (2008): 1329-1330.

[21] Ebert-May, Diane, and Janet Hodder, eds. Pathways to scientific teaching. Sunderland, Massachusetts, USA: Sinauer Associates, 2008.

[22] Pfund, Christine, Sarah Miller, Kerry Brenner, Peter Bruns, Amy Chang, Diane Ebert-May, Adam P. Fagen et al. "Summer institute to improve university science teaching." Science 324, no. 5926 (2009): 470-471.

[23] Hoffman, Christina, and Susan Goodwin. "A clicker for your thoughts: Technology for active learning." New Library World 107, no. 9/10 (2006): 422-433.

[24] Gauci, Sally A., Arianne M. Dantas, David A. Williams, and Robert E. Kemm. "Promoting student-centered active learning in lectures with a personal response system." Advances in Physiology Education 33, no. 1 (2009): 60-71.

[25] Pierce, Richard, and Jeremy Fox. "Vodcasts and active-learning exercises in a "flipped classroom" model of a renal pharmacotherapy module." American journal of pharmaceutical education 76, no. 10 (2012): 196.

[26] Osborne, Jonathan. "Arguing to learn in science: The role of collaborative, critical discourse." Science 328, no. 5977 (2010): 463-466.

[27] Millis, Barbara J. "Why faculty should adopt cooperative learning approaches." Cooperative learning in higher education: Across the disciplines, across the academy 10 (2010).

[28] Ferreri, Stefanie P., and Shanna K. O'Connor. "Redesign of a large lecture course into a smallgroup learning course." American journal of pharmaceutical education 77, no. 1 (2013): 13.

[29] Quitadamo, Ian J., Celia L. Faiola, James E. Johnson, and Martha J. Kurtz. "Community-based inquiry improves critical thinking in general education biology." CBE-Life Sciences Education 7, no. 3 (2008): 327-337.

[30] Reynolds, Rebecca, and Idit Harel Caperton. "Contrasts in student engagement, meaning-making, dislikes, and challenges in a discovery-based program of game design learning." Educational Technology Research and Development 59, no. 2 (2011): 267-289.

[31] Hoskins, Sally G., David Lopatto, and Leslie M. Stevens. "The CREATE approach to primary literature shifts undergraduates' self-assessed ability to read and analyze journal articles, attitudes about science, and epistemological beliefs." CBE-Life Sciences Education 10, no. 4 (2011): 368-378.

[32] Kozeracki, Carol A., Michael F. Carey, John Colicelli, and Marc Levis-Fitzgerald. "An intensive primary-literature-based teaching program directly benefits undergraduate science majors and facilitates their transition to doctoral programs." CBE-Life Sciences Education 5, no. 4 (2006): 340347.

[33] Labov, Jay B., Ann H. Reid, and Keith R. Yamamoto. "Integrated biology and undergraduate science education: a new biology education for the twenty-first century?." CBE-Life Sciences Education 9, no. 1 (2010): 10-16. 
[34] Udovic, Daniel, Deborah Morris, Alan Dickman, John Postlethwait, and Peter Wetherwax. "Workshop biology: demonstrating the effectiveness of active learning in an introductory biology course." AIBS Bulletin 52, no. 3 (2002): 272-281.

[35] Freeman, Scott, Sarah L. Eddy, Miles McDonough, Michelle K. Smith, Nnadozie Okoroafor, Hannah Jordt, and Mary Pat Wenderoth. "Active learning increases student performance in science, engineering, and mathematics." Proceedings of the National Academy of Sciences 111, no. 23 (2014): 8410-8415.

[36] Petress, Ken. "What is meant by" Active Learning?"." Education128, no. 4 (2008): 566-570.

[37] Machemer, Patricia L., and Pat Crawford. "Student perceptions of active learning in a large crossdisciplinary classroom." Active Learning in Higher Education 8, no. 1 (2007): 9-30.

[38] Ebert-May, Diane, Carol Brewer, and Sylvester Allred. "Innovation in large lectures: Teaching for active learning." Bioscience 47, no. 9 (1997): 601-607.

[39] Taraban, Roman, Cathy Box, Russell Myers, Robin Pollard, and Craig W. Bowen. "Effects of active-learning experiences on achievement, attitudes, and behaviors in high school biology." Journal of research in science teaching 44, no. 7 (2007): 960-979.

[40] Bot, Ludovic, Pol-Bernard Gossiaux, Carl-Philippe Rauch, and Safouana Tabiou. "'Learning by doing': a teaching method for active learning in scientific graduate education." European journal of engineering education 30, no. 1 (2005): 105-119.

[41] Haak, David C., Janneke HilleRisLambers, Emile Pitre, and Scott Freeman. "Increased structure and active learning reduce the achievement gap in introductory biology." Science 332, no. 6034 (2011): 1213-1216.

[42] Yoder, Janice D., and Catherine M. Hochevar. "Encouraging active learning can improve students' performance on examinations." Teaching of Psychology 32, no. 2 (2005): 91-95.

[43] Braxton, John M., Willis A. Jones, Amy S. Hirschy, and Harold V. Hartley III. "The role of active learning in college student persistence." New Directions for Teaching and Learning 2008, no. 115 (2008): 71-83.

[44] Crosling, Glenda, Liz Thomas, and Margaret Heagney. Improving student retention in higher education: the role of teaching and learning. Routledge, 2008.

[45] Smith, Michelle K., William B. Wood, Wendy K. Adams, Carl Wieman, Jennifer K. Knight, Nancy Guild, and Tin Tin Su. "Why peer discussion improves student performance on in-class concept questions." Science 323, no. 5910 (2009): 122-124.

[46] Martyn, Margie. "Clickers in the classroom: An active learning approach." Educause quarterly 30, no. 2 (2007): 71.

[47] Jensen, Jamie L., Tyler A. Kummer, and Patricia D. D. M. Godoy. "Improvements from a flipped classroom may simply be the fruits of active learning." CBE-Life Sciences Education 14, no. 1 (2015): $\operatorname{ar} 5$.

[48] Stone, Bethany B. "Flip your classroom to increase active learning and student engagement." In Proceedings from 28th Annual Conference on Distance Teaching \& Learning, Madison, Wisconsin, USA. 2012.

[49] Bishop, Jacob Lowell, and Matthew A. Verleger. "The flipped classroom: A survey of the research." In ASEE National Conference Proceedings, Atlanta, GA, vol. 30, no. 9, pp. 1-18. 2013. 
[50] Milman, Natalie B. "The flipped classroom strategy: What is it and how can it best be used?." Distance Learning 9, no. 3 (2012): 85.

[51] Roehl, Amy, Shweta Linga Reddy, and Gayla Jett Shannon. "The flipped classroom: An opportunity to engage millennial students through active learning." Journal of Family and Consumer Sciences 105, no. 2 (2013): 44.

[52] Abeysekera, Lakmal, and Phillip Dawson. "Motivation and cognitive load in the flipped classroom: definition, rationale and a call for research." Higher Education Research \& Development 34, no. 1 (2015): 1-14.

[53] Tune, Johnathan D., Michael Sturek, and David P. Basile. "Flipped classroom model improves graduate student performance in cardiovascular, respiratory, and renal physiology." Advances in physiology education 37, no. 4 (2013): 316-320.

[54] Auster, Ellen R., and Krista K. Wylie. "Creating active learning in the classroom: A systematic approach." Journal of Management Education 30, no. 2 (2006): 333-353.

[55] Stiggins, Rick, and Jan Chappuis. "Using student-involved classroom assessment to close achievement gaps." Theory into practice 44, no. 1 (2005): 11-18.

[56] Stiggins, Richard J., Judith A. Arter, Jan Chappuis, and Stephen Chappuis. Classroom assessment for student learning: doing it right--using it well. Assessment Training Institute, 2004.

[57] Bennett, Randy Elliot. "Formative assessment: A critical review." Assessment in Education: Principles, Policy \& Practice 18, no. 1 (2011): 5-25.

[58] Heritage, Margaret, Jinok Kim, Terry Vendlinski, and Joan Herman. "From evidence to action: A seamless process in formative assessment?." Educational Measurement: Issues and Practice 28, no. 3 (2009): 24-31.

[59] Shepard, Lorrie A. "Linking Formative Assessment to Scaffolding." Educational leadership 63, no. 3 (2005): 66-70.

[60] Cox, Kevin, Bradford W. Imrie, and Allen Miller. Student assessment in higher education: a handbook for assessing performance. Routledge, 2014.

[61] Griffin, Patrick, and Esther Care, eds. Assessment and teaching of 21st century skills: Methods and approach. Springer, 2014.

[62] Gormally, Cara, Peggy Brickman, and Mary Lutz. "Developing a test of scientific literacy skills (TOSLS): measuring undergraduates' evaluation of scientific information and arguments." CBE-Life Sciences Education 11, no. 4 (2012): 364-377.

[63] Dasgupta, Annwesa P., Trevor R. Anderson, and Nancy Pelaez. "Development and validation of a rubric for diagnosing students' experimental design knowledge and difficulties." CBE-Life Sciences Education 13, no. 2 (2014): 265-284.

[64] Semsar, Katharine, Jennifer K. Knight, Gülnur Birol, and Michelle K. Smith. "The Colorado learning attitudes about science survey (CLASS) for use in biology." CBE-life sciences education 10, no. 3 (2011): 268-278.

[65] Preszler, Ralph W., Angus Dawe, Charles B. Shuster, and Michele Shuster. "Assessment of the effects of student response systems on student learning and attitudes over a broad range of biology courses." CBE-Life Sciences Education 6, no. 1 (2007): 29-41. 
[66] Valenta, Annette, David Therriault, Michael Dieter, and Robert Mrtek. "Identifying student attitudes and learning styles in distance education." Journal of asynchronous learning networks 5, no. 2 (2001): 111-127.

[67] Suanpang, Pannee, Peter Petocz, and Walter Kalceff. "Student attitudes to learning business statistics: Comparison of online and traditional methods." Journal of Educational Technology \& Society7, no. 3 (2004).

[68] Hassanien, Ahmed. "Student experience of group work and group assessment in higher education." Journal of teaching in travel \& tourism 6, no. 1 (2006): 17-39.

[69] Orr, Susan. "Collaborating or fighting for the marks? Students' experiences of group work assessment in the creative arts." Assessment \& Evaluation in Higher Education 35, no. 3 (2010): 301313.

[70] Zhang, Bo, Lucy Johnston, and Gulsen Bagci Kilic. "Assessing the reliability of self-and peer rating in student group work." Assessment \& Evaluation in Higher Education 33, no. 3 (2008): 329340.

[71] Lage, Maureen J., Glenn J. Platt, and Michael Treglia. "Inverting the classroom: A gateway to creating an inclusive learning environment." The Journal of Economic Education 31, no. 1 (2000): 3043.

[72] César, Margarida, and Nuno Santos. "From exclusion to inclusion: Collaborative work contributions to more inclusive learning settings." European Journal of Psychology of Education 21, no. 3 (2006): 333-346.

[73] Scott, Terrance M., Kristy Lee Park, Jessica Swain-Bradway, and Eric Landers. "Positive behavior support in the classroom: Facilitating behaviorally inclusive learning environments." International Journal of Behavioral Consultation and Therapy 3, no. 2 (2007): 223.

[74] Yarime, Masaru, and Yuko Tanaka. "The issues and methodologies in sustainability assessment tools for higher education institutions: a review of recent trends and future challenges." Journal of Education for Sustainable development 6, no. 1 (2012): 63-77.

[75] Shriberg, Michael. "Institutional assessment tools for sustainability in higher education: strengths, weaknesses, and implications for practice and theory." International Journal of Sustainability in Higher Education 3, no. 3 (2002): 254-270.

[76] Kogan, Jennifer R., Eric S. Holmboe, and Karen E. Hauer. "Tools for direct observation and assessment of clinical skills of medical trainees: a systematic review." Jama 302, no. 12 (2009): 13161326.

[77] Scalese, Ross J., Vivian T. Obeso, and S. Barry Issenberg. "Simulation technology for skills training and competency assessment in medical education." Journal of general internal medicine 23, no. 1 (2008): 46-49.

[78] Tiwari, Agnes, Patrick Lai, Mike So, and Kwan Yuen. "A comparison of the effects of problembased learning and lecturing on the development of students' critical thinking." Medical education 40, no. 6 (2006): 547-554.

[79] Sinclair, Barbara, and Karen Ferguson. "Integrating simulated teaching/learning strategies in undergraduate nursing education." International Journal of Nursing Education Scholarship 6, no. 1 (2009). 
[80] Klymkowsky, Michael W., Kathy Garvin-Doxas, and Michael Zeilik. "Bioliteracy and teaching efficacy: what biologists can learn from physicists." Cell Biology Education 2, no. 3 (2003): 155-161.

[81] Jeffries, William B., and Kathryn N. Huggett. "Flipping the classroom." In An introduction to medical teaching, pp. 41-55. Springer Netherlands, 2014.

[82] Brownell, Sara E., Matthew J. Kloser, Tadishi Fukami, and Rich Shavelson. "Undergraduate biology lab courses: Comparing the impact of traditionally based" cookbook" and authentic researchbased courses on student lab experiences." Journal of College Science Teaching 41, no. 4 (2012): 36.

[83] Longo, Christopher M. "Designing inquiry-oriented science lab activities: Teachers can create inquiry-oriented science lab activities that make real-world connections." Middle School Journal 43, no. 1 (2011): 6-15.

[84] Gooding, Julia, and Bill Metz. "Folding inquiry into cookbook lab activities." Science Scope 35, no. 8 (2012): 42-47.

[85] Volkmann, Mark J., and Sandra K. Abell. "Rethinking laboratories." The Science Teacher 70, no. 6 (2003): 38.

[86] Tomasik, Janice Hall, Katelyn E. Cottone, Mitchell T. Heethuis, and Anja Mueller. "Development and preliminary impacts of the implementation of an authentic research-Based experiment in General Chemistry." Journal of Chemical Education 90, no. 9 (2013): 1155-1161.

[87] Spell, Rachelle M., Judith A. Guinan, Kristen R. Miller, and Christopher W. Beck. "Redefining authentic research experiences in introductory biology laboratories and barriers to their implementation." CBE-Life Sciences Education 13, no. 1 (2014): 102-110.

[88] Cuthbert, Denise, Dharma Arunachalam, and Dunja Licina. "'It feels more important than other classes I have done': an 'authentic'undergraduate research experience in sociology." Studies in Higher Education 37, no. 2 (2012): 129-142.

[89] Edwards, Ashley, Susan M. Jones, Erik Wapstra, and Alastair MM Richardson. "Engaging students through authentic research experiences." In Proceedings of the Australian Conference on Science and Mathematics Education (Formerly UniServe Science Conference). 2012.

[90] Makarevitch, Irina, Cameo Frechette, and Natalia Wiatros. "Authentic research experience and "big data" analysis in the classroom: maize response to abiotic stress." CBE-Life Sciences Education 14, no. 3 (2015): ar27.

[91] BIOS Program. Retrieved September 27, 2017 from Tan School of Genetics website: http://tsi.fudan.edu.cn/students/undergraduate-students/bios/ (n.d.)

[92] Labov, Jay B. "From the National Academies: the challenges and opportunities for improving undergraduate science education through introductory courses." Cell Biology Education 3, no. 4 (2004): 212-214.

[93] Wieman, Carl. "Why not try a scientific approach to science education?." Change: The Magazine of Higher Learning 39, no. 5 (2007): 9-15. 